\title{
Influence of Provider Interaction on Patient's Readiness Toward Audiological Services and Technology
}

\author{
Amyn M. Amlani ${ }^{1}$ \\ ${ }^{1}$ Audigy Group, Vancouver, WA \\ J Am Acad Audiol 2020;31:342-353.
}

Address for correspondence Amyn M. Amlani, Audigy Group, Vancouver, WA 98684 (e-mail: aamlani@audigy.com).

\begin{abstract}
Background Patients and providers recognize the importance of patient-centered care. Clinical interactions, however, suggest that audiologists maintain their traditional provider-centered approach.

Purpose The primary purpose of this study was to assess the degree to which provider interaction influenced patient readiness toward audiological services using the neobehavioral concept of need recognition described in consumer decision-making.

Research Design We used a randomized, within-group experimental approach using survey responses to quantify predisposed expectations on ten dimensions toward service and technology provision 2 weeks before and 2 weeks after an audiological assessment. Responses were also categorized as a function of the respondent-perceived professional setting of the provider (medical, rehabilitation, and consumer electronics).

Study Sample Survey respondents included 618 adults $\{186$ males (mean age $=63.1$ years; standard deviation $[S D]=5.3$ ) and 432 females [mean age $=58.4$ years; $\mathrm{SD}=6.2]$ from across the United States.

Data Collection and Analysis Data were analyzed using two approaches. First, we used a two-step cluster analysis procedure that revealed natural groupings (i.e., profiles) of respondent characteristics of the ten dimensions. Second, we compared within-group mean differences between pre- and postappointment responses using a univariate analysis of variance, with mean differences reported as a function of professional setting and preappointment responses serving as the control condition. Results Results revealed that the predisposed expectation profiles among the ten dimensions differed among the professional settings, with rehabilitation having the highest mean response values and consumer electronics having the least mean response values. A descriptive analysis indicated that respondents in the rehabilitation and medical settings presented the greatest interest in amplification before the patient-provider interaction, but the least interest afterward. In addition, postappointment analyses revealed that providers failed statistically to meet patients' predisposed

\section{Keywords}

- analysis of variance

- cluster analysis

- consumer decisionmaking

- patient-centered care

expectations in all three settings.

Conclusions Overall, most respondents' predisposed expectations were unmet during their interaction with an audiologist. These expectations differed across professional settings, with the greatest unmet expectations observed in the rehabilitative and medical settings. Patient readiness is influenced by the behavior of the provider which, at present, appears to be a barrier to patients' acceptance of treatment options.
\end{abstract}

Copyright $\odot 2020$ by the American Academy of Audiology. All rights reserved. Thieme Medical Publishers, Inc., 333 Seventh Avenue, New York, NY 10001, USA. Tel: +1(212) 760-0888
DOI https://doi.org/ 10.3766/jaaa.19051. ISSN 1050-0545. 


\section{Introduction}

The Institute of Medicine (2001) defines patient-centered care (PCC) as the provision of care that is respectful of and responsive to an individual's preference, needs, and values, and ensures that patient values guide clinical decisions. PCC originated from the counseling and psychotherapy work of Rogers (1951) and diverges from the traditional provision of the provider-centered approach, where the patient relied on the health-care professional to render unilateral treatment and management decisions for a given health-related condition. Instead, PCC is a process 7 whereby patients participate actively in their own treatment and management of a health condition (Barry and Edgman-Levitan). ${ }^{3}$ PCC is being advocated in the evidence-based management of chronic health conditions, including hearing health (Boisvert et al). ${ }^{6}$

Several health professions-such as medicine (Santana et al) ${ }^{44}$ and nursing (McCormack and McCance) ${ }^{32}$-have developed PCC frameworks that lend to professional guidelines and methodologies, allowing for oversight in determining the quality and degree to which a provider is using the process. The benefit of a developed PCC framework and methodology yields increased professional service advancements. For example, in the treatment of asthma, Qamar et al (2011) report that the PCC framework yields improved patient satisfaction, reduced negativity toward providers and medication regimens, increased adherence to medication use, improved patient quality of life, and fewer emergency room visits than the providercentered approach.

In audiology, a recommended framework of PCC is yet to be developed formally. Empirical efforts have assessed the conceptualization of PCC to audiological rehabilitation (Grenness et al), ${ }^{11}$ the use of evidence-based practice to guide provider PCC rehabilitation decision-making (Boisvert et al), ${ }^{6}$ and provider-patient factors that influence hearing healthcare decisions (Poost-Foroosh et al; ${ }^{35,36}$ Grenness et al). ${ }^{13}$

For audiology to transition to a PCC model, the profession must assess its present-day practices. Clinical interactions with patients reveal that providers maintain their traditional provider-centered approach as evidenced by (a) an absence of relationship-building with their patients (Grenness et al), ${ }^{13}(\mathrm{~b})$ a lack of empathy when patients present psychosocial concerns expressed with a negative emotional stance (Ekberg et al; ${ }^{11}$ Grenness et al), ${ }^{13}$ (c) a failure to include family member input as part of the treatment and management process of patient health care (Ekberg et al), ${ }^{13}$ (d) a failure to acknowledge patients' emotional responses during the decision-making process with respect to hearing aid cost options (Ekberg et al), ${ }^{10}$ and (e) not promoting an equal opportunity for patients to participate actively in their own treatment and management of their hearing impairment (Grenness et al). ${ }^{13}$

One aspect of the provider-patient interaction that remains unclear is the extent to which the audiologist influences the patient's readiness toward treatment interventions. Recently, Ekberg et al (2016) explored patients' readiness toward audiological rehabilitation using the transtheoretical model (Prochaska and DiClemente). ${ }^{38}$ (This health-related behavior model quantifies changes in an individual's attitudes, actions, and intentions as the individual cycles through the decision-making process toward an intentional behavior change. The process of the change involves five stages: (a) precontemplation (i.e., no thoughts or plans to change a behavior), (b) contemplation (i.e., aware of the problem that the behavior creates), (c) preparation (i.e., intended action to be taken), (d) action (i.e., behavior modification), and (e) maintenance (i.e., sustained healthy behavior). The findings from the model aid the clinician in determining an individual's stage of readiness to change, as well as a basis for counseling and intervention.) Results revealed that patient readiness to a hearing aid trial could be observed through the interaction with the audiologist; that is, patients categorized in the precontemplation stage displayed an increased resistance toward the recommendation of hearing aids compared with patients categorized in the contemplation stage or preparation stage. Likewise, Laplante-Levesque et al (2012) evaluated the degree to which patients complied with the shared- decision treatment options (i.e., uptake of hearing aids, completion of communication program, and no intervention) offered by their provider. Results revealed that only $25 \%$ of impaired listeners followed through with their initial treatment decision, although $40 \%$ of impaired listeners chose the no-intervention option, many of whom were classified in the contemplation stage.

A critique of both the Laplante-Levesque et al (2012) and Ekberg et al (2016) studies is the application of the transtheortical model (Prochaska and DiClemente) ${ }^{38}$ to assess behavioral changes in patient perception. Health-behavior models-such as the Health Belief Model (Rosenstock), ${ }^{41}$ the theory of planned behavior (Fishbein and Ajzen), ${ }^{14}$ and the transtheoretical model-have been applied traditionally to hearing health to assess and predict changes in knowledge, attitudes, and behavior (Laplante-Levesque, Hickson, et al; ${ }^{26}$ Saunders et al; ${ }^{45}$ Ekberg et al). ${ }^{12}$ A recent review of these healthbehavior models revealed that the models' predictive capability lacks sensitivity in quantifying changes in performance in hearing health, and thus, new approaches should be considered (Coulson et al). ${ }^{8}$ The basis of this review prompted us to undertake the present study to quantify the degree to which a provider influences a patient's readiness toward audiological services and treatment using the neobehavioral concept of need recognition described in consumer decision-making.

\section{Consumer Decision-Making Model}

Need recognition is the fundamental concept described in the consumer decision-making model (Blackwell et al). ${ }^{5}$ This concept is predicated on the information processing perspective, where the interaction between the consumer and stimuli in the environment is an ongoing cognitive process that the consumer develops beliefs and attitudes toward the environment (0stergaard and Jantzen). ${ }^{34}$ These beliefs are evaluated introspectively based on (a) a need (i.e., problem) and (b) the motivation, ability, and opportunity provided by the environment to resolve-or lessen- the need. - Figure 1 illustrates this concept. 


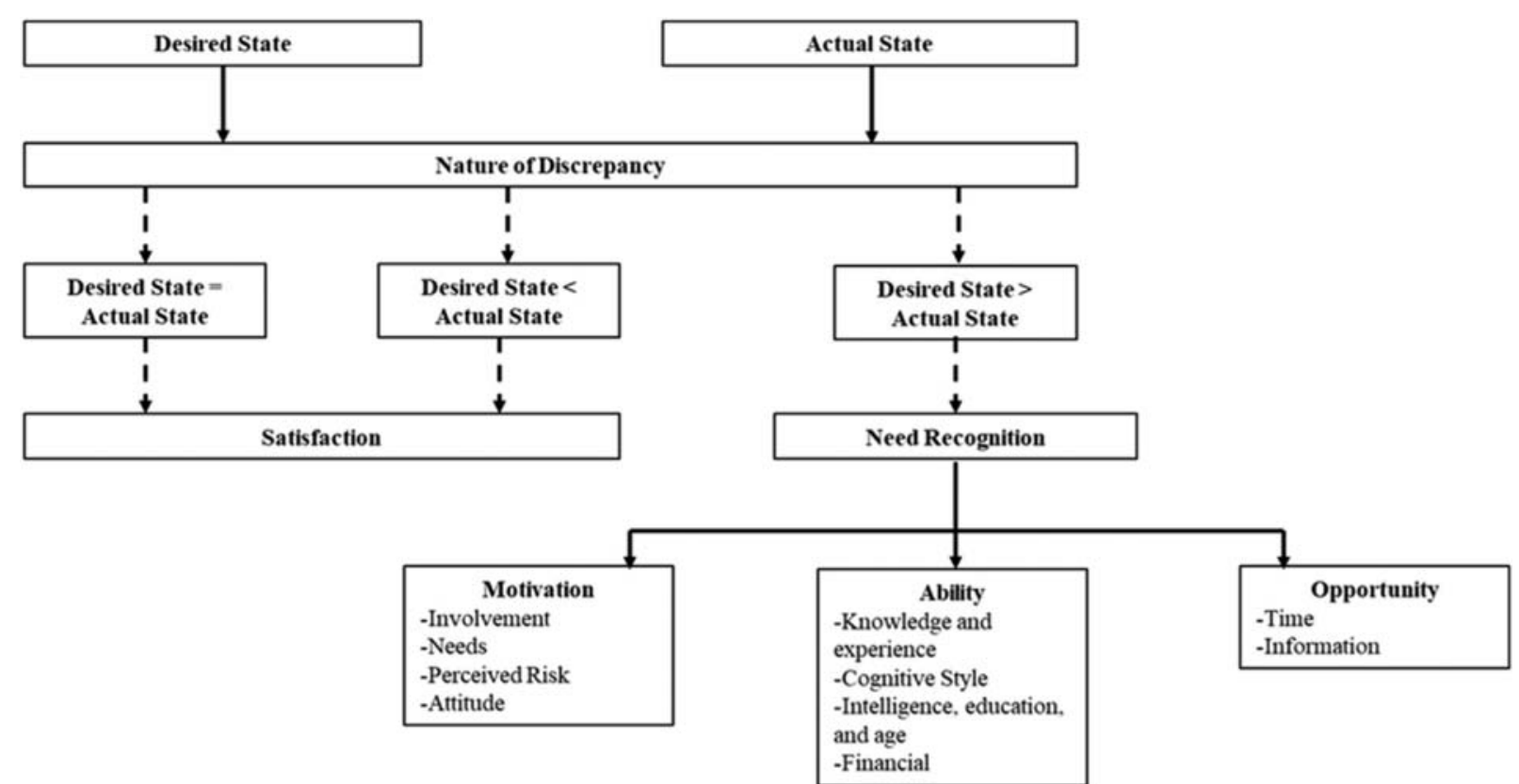

Fig. 1 Schematic depicting the concept of need recognition as part of the consumer decision-making (see text for details).

\section{Need}

Psychocognitively, need is assessed by comparing the individuals' desired state with their actual, or present, state. In audiology, the patients' magnitude of desired state (e.g., ability to hear conversational speech) must exceed the psychological threshold for the actual state (e.g., threshold at which hearing sensitivity reduces the ability to hear conversational speech) for treatment options to be considered. Conversely, when the magnitude for the desired state (e.g., ability to hear conversational speech) is less than or equal to the patients' psychological threshold for the actual state (e.g., threshold at which hearing sensitivity reduces the ability to hear conversational speech), patients perceive satisfaction with their actual state, diminishing the need to consider treatment options. (For additional details on consumer decision-making and hearing aid adoption, the reader is referred to Amlani.) ${ }^{1}$

A brief description of how need recognition is shaped by the factors of motivation, ability, and opportunity is provided in the following paragraphs (-Figure 1).

\section{Motivation}

Motivation, or an individual's behavior directed toward a desired outcome, is dependent on need recognition; that is, a need is activated when there is a discrepancy between individuals' current state and their desired state. As the discrepancy to achieve the desired state increases, motivation activates a condition of arousal referred to as drive (Blackwell et al). ${ }^{5}$ This drive (i.e., desired state) represents the goal(s) of the individual.

Several factors are known to influence motivation. For example, Schiffman and Wisenblit (2013) distinguish between rational and emotional motives, where the former implies goals based on objective criteria (e.g., price and aesthetics) and the latter implies goals based on subjective criteria (e.g., culture and value). Motivation is also influenced by factors, such as the individual's environment, experiences, values, and interactions with others.

\section{Ability}

One aspect of ability is the influence of emotion on cognition. Research from cognitive psychology suggests that emotion and cognitive processing are interdependent, such that emotion modulates and mediates basic cognitive processes (Storbeck and Clore). ${ }^{48}$ In the context of health-related decisions, emotion has been found to be an important predictor of engaging in health-protective behaviors (e.g., safer sex practices, exercise, and healthy diet) through its effects on self-efficacy (i.e., perceived ability to manage one's health) (Salovey et al). ${ }^{43}$

Research further indicates that once an attitude is predisposed, changing the predisposition is difficult (Wilson et al). ${ }^{51}$ Although new attitudes can override predisposed attitudes, the initial predisposition is never replaced, yielding a concept of dual attitudes. According to Wilson et al (2000), dual attitudes are a cognitive assessment of the same object that can result in differing attitudes.

\section{Opportunity}

Two factors that influence need recognition are time and type of information. Kirande et al (2011) found that time influences consumer purchasing behavior. Specifically, individuals who have insufficient time to attend to product and service information are less likely to problem-solve. In this case, individuals who elect to adopt a product or service will either select the well-known brand because they do not take the time to consider alternatives, or they will select the least expensive product and risk buyers' remorse (i.e., cognitive dissonance). Furthermore, research indicates that individuals are less likely to adopt a service or product once they leave the premises (Kirande et al). ${ }^{23}$ For individuals who are time-constrained, on 
the other hand, additional time to process the information may be beneficial.

The amount and type of information presented, also, can affect individuals' processing ability. Individuals view messages containing a picture without words, often seen in trade journals, as ambiguous and difficult to process (Hibbard). ${ }^{21}$ Furthermore, large amounts of information that require sorting are viewed as complex. Most importantly, information that is technical and quantitative is more difficult for individuals to process than information that is nontechnical and qualitative (Amlani et al). ${ }^{2}$

\section{Method}

\section{Participants}

A total of 618 adult participants, who self-identified with impaired hearing, completed a pre- and postonline survey of their professional experience with an audiologist, including their interest in pursuing amplification technology. Of the 618 participants, 186 were males (mean age $=63.1$ years; standard deviation $[\mathrm{SD}]=5.3$ ) and 432 were females (mean age $=58.4$ years; $S D=6.2$ ). Participants were recruited through a national hearing care program that provided access to a network of providers, including audiologists, hearing instrument specialists, and otolaryngologists.

Participants' responses were represented from every state except Alaska, Delaware, Iowa, Mississippi, Nevada, New Mexico, North Dakota, and Wyoming. States with the highest number of participants were Michigan (41), Arizona (39), New York (37), Texas (37), California (35), and Florida (33).

\section{Patient-Centered Readiness Survey}

We created a 16-item online survey in Qualtrics. The first survey item included an Institutional Review Board-approved consent form. Once consent was provided, the participant was provided the remaining survey items. Items $2-4$ asked respondents to report their date of birth, gender, and the state in which they resided. Item 5 queried participants to rate their perception of the type of service they would be receiving from their provider as either (1) medical, (2) rehabilitation, or (3) consumer electronics. We included this question based on the work of Beattie and Nelson (2008), who report that patients' perception toward the type and quality of care they will receive is predisposed based on factors such as the provider's website, practice location (e.g., medical plaza, stand-alone clinic), and accepted forms of payment (e.g., insurance, credit card, financing availability). Questions 6-15 probed patients' perceptions toward their provider for ten dimensions using a scale ranging from 1 (not important) to 10 (important). The ten dimensions were established from the literature and are listed in - Table 1, along with their definitions and categorical placement with respect to the need recognition (i.e., motivation, ability, and opportunity). Last, question 16 solicited a yes/no response from participants on whether they were interested in obtaining information about hearing aids as part of the rehabilitation and treatment process.

Table 1 Listing and Corresponding Definition of the Ten Dimensions Assessed in This Study

\begin{tabular}{|c|c|}
\hline Dimension & Competency \\
\hline Competency* $^{*}$ & $\begin{array}{l}\text { Patients' perception of providers' efficiency in achieving good treatment outcomes (Thom and } \\
\text { Campbell, } 49 \text { as referenced in Preminger et } \mathrm{al}^{37} \text { ) }\end{array}$ \\
\hline Confidentiality $^{\dagger}$ & $\begin{array}{l}\text { Patients'trust that the provider will protect sensitive information (Thom et al, }{ }^{50} \text { as referenced in } \\
\text { Preminger et } \mathrm{al}^{37} \text { ) }\end{array}$ \\
\hline Empathy $^{\dagger}$ & $\begin{array}{l}\text { Providers' ability to identify with the feelings of patients, communicate the understanding of their } \\
\text { difficulty, and provide support (Stepien and Baernstein }{ }^{47} \text { ) }\end{array}$ \\
\hline Health promotion ${ }^{\ddagger}$ & $\begin{array}{l}\text { Provision of clear, comprehensible, communication to ensure that patients receive unbiased and } \\
\text { culturally appropriate information that lends to an educated choice regarding treatment (Gilligan } \\
\text { and Weinstein }{ }^{16} \text { ) }\end{array}$ \\
\hline Integrated caret & $\begin{array}{l}\text { Sharing of health information among professionals in different professions that establishes a } \\
\text { comprehensive treatment plan to address the biological, psychological, and social needs of the } \\
\text { patient (Gröne and Garcia-Barbero }{ }^{17} \text { ) }\end{array}$ \\
\hline Family/friend support* & Provider involves family/friends as part of the treatment process (Ekberg et al ${ }^{13}$ ) \\
\hline 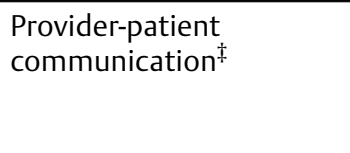 & $\begin{array}{l}\text { The provider imparts information that is complete, accurate, timely, unambiguous, and without a } \\
\text { priori expectations, in addition to appropriate nonverbal behavior. In addition, the patient is } \\
\text { afforded the opportunity to facilitate in the communication process with open-ended responses } \\
\left(G r e n n e s s \text { et } \mathrm{al}^{13} \text { ) }\right.\end{array}$ \\
\hline Respect* & $\begin{array}{l}\text { The provider delivers services that are respectful of and responsive to the health beliefs, practices, } \\
\text { and cultural and linguistic needs of diverse patients (Saha et } \mathrm{al}^{42} \text { ) }\end{array}$ \\
\hline Shared decision-making* & $\begin{array}{l}\text { A process in which providers and patients work together on treatment options based on clinical } \\
\text { evidence that balances risks and expected outcomes with patient preferences and values (Gilligan } \\
\text { and Weinstein }{ }^{16} \text { ) }\end{array}$ \\
\hline Trust $^{\dagger}$ & The patient's confidence that the provider will do what is best for the patient (Preminger et al $^{37}$ ) \\
\hline
\end{tabular}




\section{Procedures}

An email soliciting participation was forwarded to 6,200 members (i.e., patients) of a national hearing care program between September 2015 and August 2016. This email requested that members interested in having their hearing sensitivity assessed select a network provider of their choice and schedule an appointment. Before the appointment, a second email, which was blinded to the investigator, requested that members complete an online survey of their appointment expectations 2 weeks before their scheduled appointment. Specifically, potential participants were instructed to share their predisposed expectations of the initial appointment including the professional setting of the provider and their interest in amplification services and technology. A third email, also blinded to the investigator, was forwarded to those individuals who completed the preappointment survey asking these members to rate their postinteraction experience with the provider, including their interest in amplification services and technology. In November 2016, all completed survey results were provided to the investigator for analyses.

A total of 1,273 participants completed the pre- and postsurvey components; of these, 618 reported that their primary provider was an audiologist. (An additional 573 participants indicated being seen by a hearing instrument specialist, and 142 participants were unsure of the credentials of the professional who treated them. The former set of data will be compared with the data reported in this study in a future study.)

The pre- and postsurveys were completed in, on average, 7.6 days $(S D=3.8)$ and 3.3 days $(S D=2.1)$, respectively, relative to the initial appointment. Participants were not provided an incentive for their participation.

\section{Statistical Approach}

Participant responses were analyzed as a function of professional setting using a two-step cluster analysis procedure (IBM SPSS Statistics, version 25; Armonk, NY). This exploratory procedure reveals natural groupings (i.e., clusters) within a dataset that describes respondent characteristics toward an outcome, such as consumer buying habits (Koutsimanis et al) 24 and physician-patient interaction (Lutfey et al). ${ }^{28}$ Clusters were arranged using a Schwarz criterion (i.e., Bayesian information criterion) and a log-likelihood distance measure, the latter of which presumes (a) continuous variables are normally distributed, (b) categorical variables are multinomial, and (c) the cluster variables in the model are independent (Frederick and Prins). ${ }^{15}$ To compare mean differences between pre- and postappointment responses, we applied a univariate analysis of variance (ANOVA) at an alpha of 0.05 . Specifically, mean differences are reported as a function of professional setting (i.e., within-group), with each preappointment responses serving as a control condition.

\section{Results}

A total of 618 participants reported that their primary provider was an audiologist, whose primary services were perceived as being provided in one of three professional settings: medical $(n=142)$, rehabilitative $(n=389)$, and consumer electronics $(n=87)$. Additional results are discussed in the following paragraphs with respect to the professional setting.

\section{Medical Setting}

- Table 2 displays respondents' pre- and postappointment perception of their encounter with a provider in a medical setting. In this setting, 142 respondents actively sought out a provider to assess their selfperceived hearing deficit, with 95 respondents, or $67 \%$ of this sample, indicating a favorable attitude toward amplification.

Postappointment responses, however, indicated that only 50 respondents-of the possible 142 (i.e., 35\%) - remained interested in returning to the audiologist for additional management and treatment of their hearing health care. With respect to patient interest in amplification, postappointment responses revealed that the initial sample size of 95 respondents was reduced to 43 . Of these 43 respondents, 36 were tallied from the initial 95 respondents who reported a positive predisposition toward amplification and the remaining 7 positive responses toward amplification were provided by respondents who did not report a po sitive disposition toward amplification before the audiological appointment.

\section{Cluster Analysis}

-Figure 2 displays the results from the cluster analysis of overall respondent ratings toward patient-provider interaction as a function of professional setting. On the graph, bars with a predictive performance closer to 1.00 are considered highly important, and values closer to 0.00 are less

Table 2 Descriptive Analysis of Respondents' Pre- and Postappointment Survey Perception toward Audiological Treatment and Amplification as a Function of Professional Setting

\begin{tabular}{|l|l|l|l|l|l|l|}
\hline \multirow{2}{*}{ Respondent Perception } & \multicolumn{2}{l|}{ Medical (n=142) } & \multicolumn{2}{l|}{$\begin{array}{l}\text { Rehabilitation } \\
(\mathbf{n = 3 8 9 )}\end{array}$} & $\begin{array}{l}\text { Consumer Electro- } \\
\text { nics (n= 87) }\end{array}$ \\
\cline { 2 - 7 } & Pre & Post & Pre & Post & Pre & Post \\
\hline Receptive toward treatment & 142 & 50 & 389 & 173 & 87 & 64 \\
\hline Apathy toward treatment & 0 & 92 & 0 & 216 & 0 & 23 \\
\hline Receptive toward amplification & 95 & 36 & 187 & 29 & 72 & 49 \\
\hline Apathy toward amplification & 47 & 40 & 202 & 197 & 15 & 4 \\
\hline
\end{tabular}




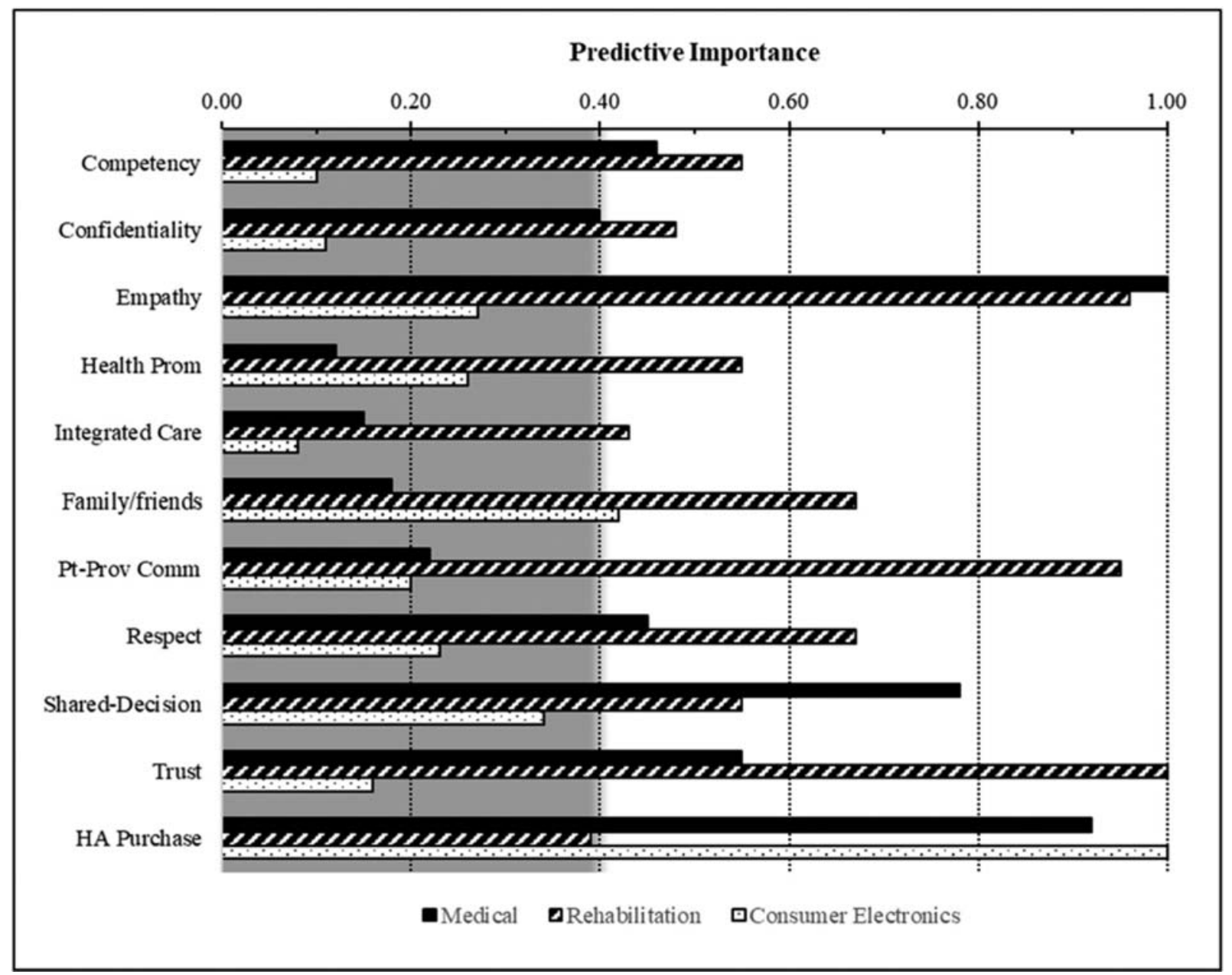

Fig. 2 Cluster groupings of overall respondent ratings across dimensions toward the patient-provider interaction as a function of professional setting.

important. In addition, a cutoff value of 0.40 was used, based on the work of Martic-Kehl et al (2015), where values above this level were regarded as a valid representation of the importance for a given dimension.

For respondents being seen by an audiologist in a medical setting-denoted by the solid black bars in - Figure 2-the dimensions of empathy, shared decisionmaking, trust, competency, and respect were the most important attributes sought in a provider. Furthermore, note that the dimension of hearing aid purchase yielded a response closer to 1.00 , suggesting that patients who are seen by a provider in a medical setting have an increased perceived importance toward amplification.

\section{Pre- versus Postappointment Analyses}

- Table 3 displays the mean and 95-percent confidence interval (CI95) for participant responses for each dimension obtained pre- and postappointment. Results indicated a statistically significant reduction in postappointment responses compared with the preappointment for six (of a possible ten) dimensions: competency $\left[F_{(1,140)}=13.55\right.$, $p<0.01]$, empathy $\left[F_{(1,140)}=63.74, p<0.001\right]$, integrated care $\left[F_{(1,140)}=5.75, p<0.05\right]$, provider-patient communication $[F(1,140)=4.81, p<0.05]$, respect $[F(1,140)=61.33$, $p<0.001]$, and trust $\left[F_{(1,140)}=16.12, p<0.001\right]$.
A post-hoc analysis across dimensions, shown in - Figure 3, displays quartiles (i.e., shaded rectangle) and respondents' response range (i.e., error bars). The filled circles represent the preappointment mean responses among all respondents. The open circles and open triangles denote postappointment mean responses (CI95 represented by dashe d line) where respondents were positive and negative toward amplification, respectively. Statistically, the dimensions of empathy, integrated care, family and friends, patient-provider communication, and shared decision-making were found to be significantly $(p<0.05)$ lower between the preappointment (i.e., filled circles) and postappointment (i.e., open circles) for respondents with a positive outlook toward amplification. For respondents with a negative outlook toward amplification, the dimensions of competency, confidentiality, empathy, family and friends, respect, shared decision-making, and trust were statistically $(p<0.05)$ lower between the pre- and postappointment.

\section{Rehabilitation Setting}

The sample size for the rehabilitation setting yielded 389 respondents. Of this sample, $48 \%$, or 187 of the 389 respondents, indicated an interest in amplification before being seen by a provider (-Table 2 ).

Postappointment responses, however, revealed that of the 389 respondents, only 173 (i.e., a 55\% decrease) felt the need to 
Table 3 Mean and C195 Comparison between Pre- and Postappointment Participant Responses for Each Dimension as a Function of Professional Setting

\begin{tabular}{|l|l|l|l|l|l|l|}
\hline \multirow{2}{*}{ Dimension } & \multicolumn{2}{l}{ Medical } & \multicolumn{2}{l|}{ Rehabilitation } & \multicolumn{2}{l|}{ Consumer Electronics } \\
\cline { 2 - 7 } & Pre & Post & Pre & Post & Pre & Post \\
\hline Competency & $7.73(0.82)$ & $4.87^{*}(1.05)$ & $7.40(0.93)$ & $4.93^{*}(1.17)$ & $6.13(0.83)$ & $5.00(0.74)$ \\
\hline Confidentiality & $7.27(1.09)$ & $5.20(0.81)$ & $8.20(0.80)$ & $5.73^{*}(1.04)$ & $6.00(0.83)$ & $4.93(0.73)$ \\
\hline Empathy & $8.07(0.75)$ & $3.73^{*}(0.75)$ & $8.67(0.56)$ & $3.66^{*}(0.97)$ & $6.40(0.60)$ & $5.11^{*}(0.50)$ \\
\hline Health promotion & $6.80(0.84)$ & $6.70(0.97)$ & $7.12(0.94)$ & $3.53^{*}(1.09)$ & $6.52(0.60)$ & $5.26(0.62)$ \\
\hline Integrated care & $6.13(0.81)$ & $4.51^{*}(1.03)$ & $7.87(0.85)$ & $5.44^{*}(0.99)$ & $7.67(0.49)$ & $7.04(0.56)$ \\
\hline Family/friend support & $5.56(0.66)$ & $5.02(0.92)$ & $8.53(0.72)$ & $4.54^{*}(0.59)$ & $5.76(0.46)$ & $5.34(0.62)$ \\
\hline Provider-patient communication & $6.46(0.78)$ & $4.67^{*}(0.89)$ & $8.80(0.51)$ & $4.00^{*}(0.88)$ & $7.13(0.74)$ & $5.80(0.58)$ \\
\hline Respect & $7.70(0.82)$ & $4.86^{*}(1.05)$ & $7.53(1.10)$ & $4.60^{*}(0.95)$ & $6.18(0.76)$ & $5.20^{*}(0.51)$ \\
\hline Shared decision-making & $7.60(0.81)$ & $3.72^{*}(0.87)$ & $6.80(1.12)$ & $4.06^{*}(1.25)$ & $6.66(0.77)$ & $4.93^{*}(0.49)$ \\
\hline Trust & $7.25(0.82)$ & $4.46^{*}(1.01)$ & $8.07(0.75)$ & $3.33^{*}(0.73)$ & $6.00(0.65)$ & $4.86^{*}(0.83)$ \\
\hline
\end{tabular}

*Denotes statistical significance $(p<0.05)$.

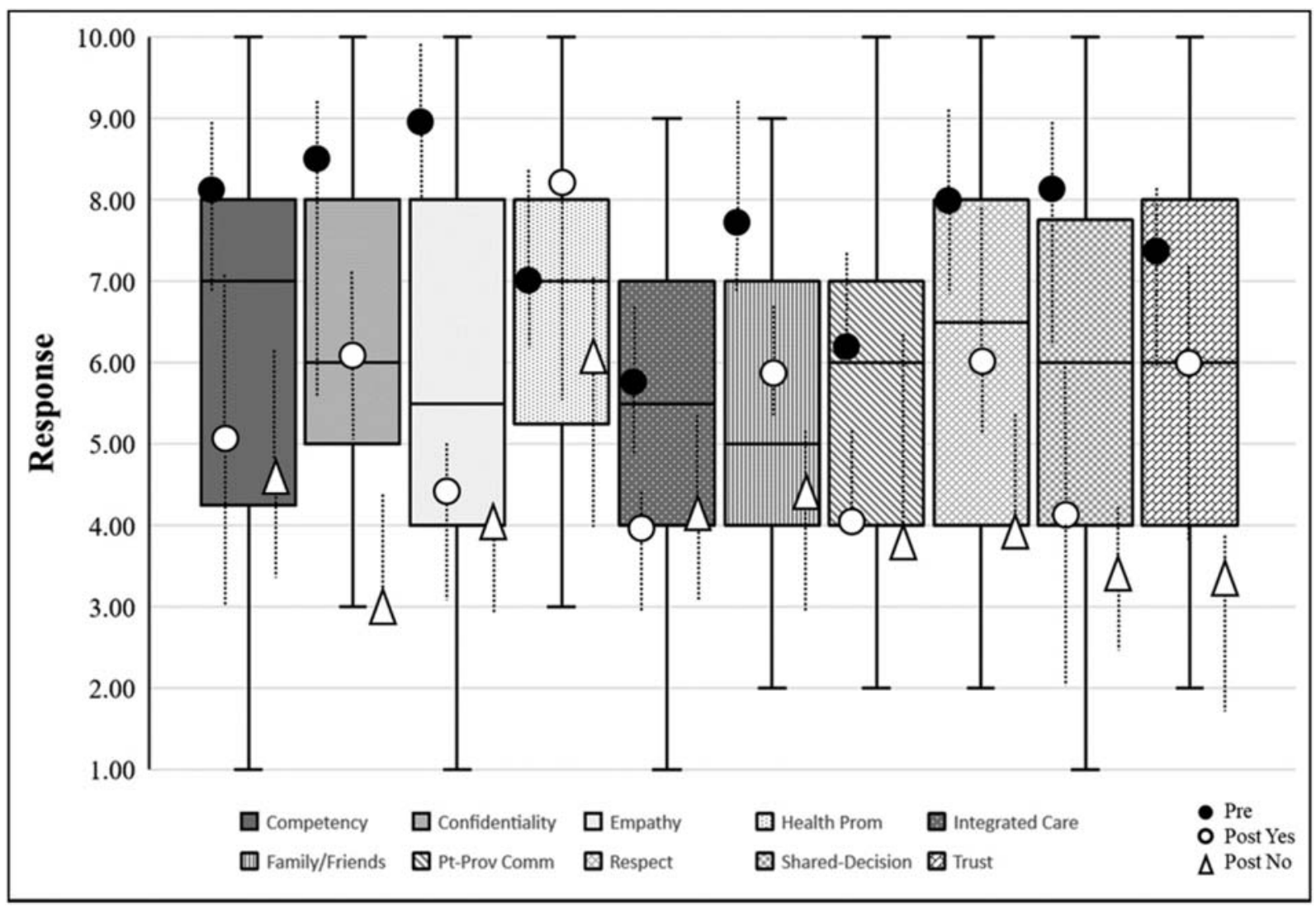

Fig. 3 Post-hoc results from the univariate ANOVA that shows quartiles (i.e., shaded rectangle) and respondents' response range (i.e., error bars) for the medical setting. The filled circles represent the preappointment mean responses among all respondents, and the open circles and open triangles, along with dashed lines representing $\mathrm{Cl}_{95}$, denote postappointment mean responses where respondents were positive and negative toward amplification, respectively.

continue being treated by a provider regarding their hearing health-care needs. In addition, postappointment responses yielded a mere 34 respondents, or $18 \%$, maintained an interest toward amplification, from the preappointment sample size of 187. Of these 34 respondents, 29 were identified as initially having a positive disposition toward amplification, although 5 others reversed their initial negative perception toward amplification after their interaction with an audiologist.

\section{Cluster Analysis}

- Figure 2 displays overall participant responses- denoted by the bars having a diagonal upward stripe-toward the 
dimensions of a patient-provider interaction that occurs in a rehabilitation setting. The rehabilitation setting yielded all 10 factors of predictive importance. Interestingly, purchasing a hearing aid was not found to be of importance to the average respondent, as indicated by the importance factor $<0.40$. This latter finding was unexpected.

\section{Pre- versus Postappointment Analyses}

Mean differences, shown in - Table 3, indicate a statistically significant reduction in postappointment responses compared with the preappointment for all ten dimensions: competency $\left[F_{(1,385)}=10.43, p<0.01\right]$, confidentiality $\left[F_{(1}\right.$, $385)=15.80, p<0.001]$, empathy $\left[F_{(1,385)}=74.87, p<0.001\right]$, health promotion $\left[F_{(1,385)}=21.55, p<0.001\right]$, integrated care $\left.\left[F_{(1,} \quad 385\right)=12.94, \quad p<0.01\right]$, family/friends $\left[F_{(1}\right.$, $385)=41.58, p<0.001]$, provider-patient communication $\left.\left[F_{(1,} 385\right)=85.79, p<0.001\right]$, respect $\left[F_{(1,} 385\right)=15.67$, $p<0.001]$, shared decision-making $\left[F_{(1,} 385\right)=10.23$, $p<0.01]$, and trust $\left[F_{(1,385)}=16.12, p<0.001\right]$.

A post-hoc analysis across dimensions is displayed in - Figure 4. First, note that the preappointment response means, denoted by the filled circles, the range between 7.75 and 9.25. This range of values was the highest of the three professional settings assessed in this study, meaning that patients entered this setting with the highest predisposed perceptions toward the provider. The dimensions of confi- dentiality, empathy, integrated care, family and friends, patient-provider communication, respect, and trust were found to be statistically $(p<0.05)$ lower between the pre- and postappointment for respondents with a positive outlook toward amplification. For respondents with a negative outlook toward amplification, each of the ten dimensions was statistically $(p<0.05)$ lower between the pre- and postappointment.

\section{Consumer Electronic Setting}

Eighty-seven respondents indicated being seen by a provider whose primary professional setting was perceived as representative of consumer electronics (-Table 2). Of this sample, $83 \%$ (i.e., 72 of the 87 respondents) indicated an interest in amplification before being seen by a provider.

Postappointment responses, however, revealed that 64 of the 87 respondents in this professional setting (i.e., 74\%) remained interested in seeking treatment actively by an audiologist. Furthermore, postappointment responses showed a reduction of 23 respondents-from an initial tally of 73 respondents-who initially had a positive perception toward amplification. Interestingly, the total sum of respondents who remained interested in pursuing amplification equated to 60 , with 49 stemming from the initial tally combined with an additional 11 respondents who reversed their initial negative perception toward amplification after their interaction with an audiologist.

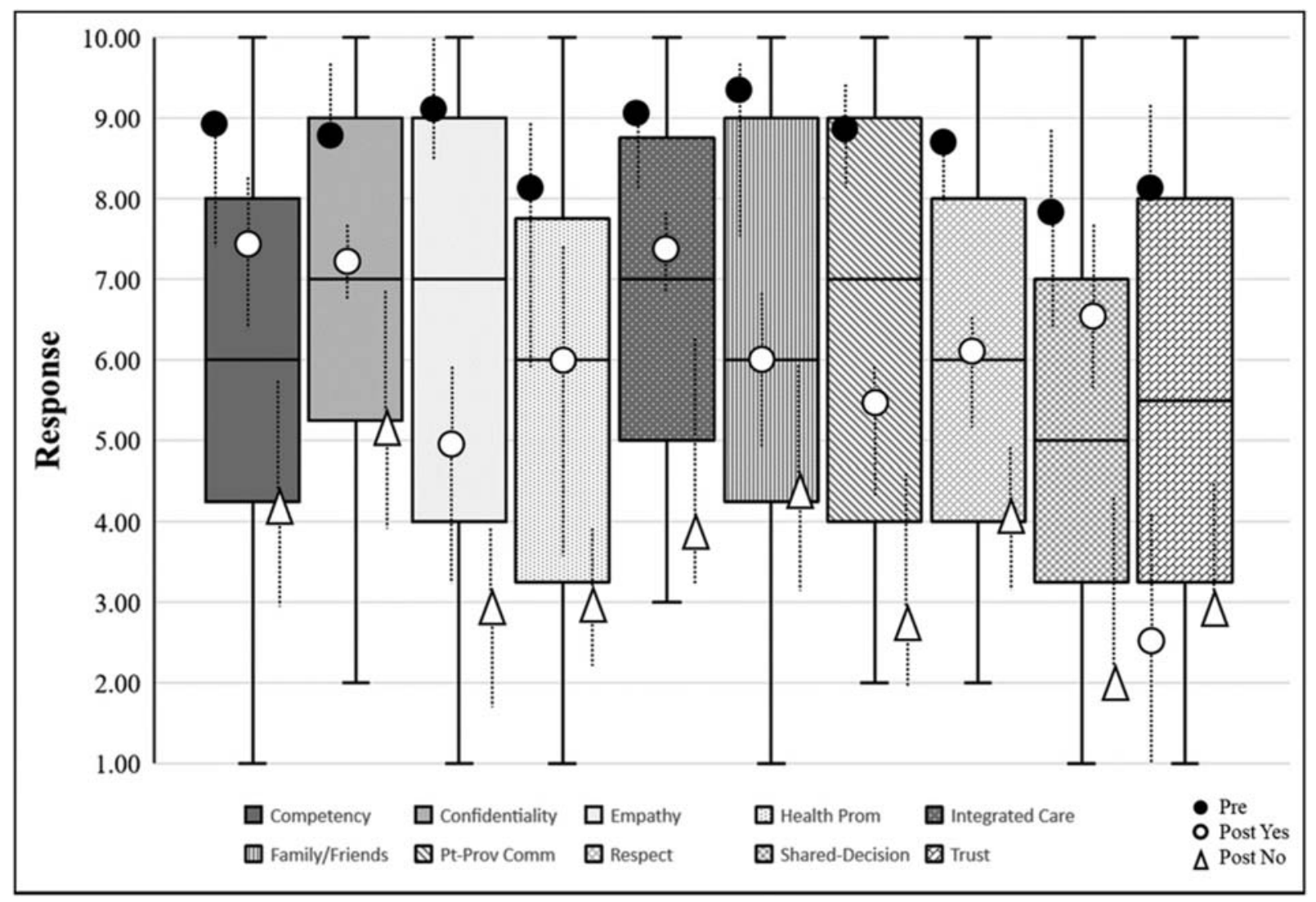

Fig. 4 Post-hoc results from the univariate ANOVA that shows quartiles (i.e., shaded rectangle) and respondents' response range (i.e., error bars) for the rehabilitation setting. The filled circles represent the preappointment mean responses among all respondents, and the open circles and open triangles, along with dashed lines representing $\mathrm{Cl}_{95}$, denote postappointment mean responses where respondents were positive and negative toward amplification, respectively. 


\section{Cluster Analysis}

- Figure 2 displays participant responses toward the patientprovider interaction in a consumer electronic setting. Note that only two factors-depicted as a white bar with black dots -yielded a value $>0.40$ : family/friends and hearing aid purchase. These lone factors are consistent with the concept of social influence on purchasing behavior, whereby the presence of family/friends increases the probability of a retail transaction (Childers and Rao). ${ }^{7}$

\section{Pre- versus Postappointment Analyses}

Mean differences for this professional setting are shown in - Table 3. For the preappointment response means, denoted by the filled circles, note that responses had a narrow range (i.e., between roughly 5.75 and 7.5 ). This range of values was the lowest among the professional settings assessed in this study and suggests that patients entered this setting with lower expectations from the provider. Results for the postappointment responses indicate a statistically significant reduction in expectation compared with the preappointment in four of the ten dimensions: empathy $\left[F_{(1,85)}=10.11, p<0.01\right]$, respect $\left[F_{(1,85)}=4.15, p=0.05\right]$, shared decision-making $\left[F_{(1}\right.$, 85) $=14.25, p<0.01]$, and trust $\left[F_{(1,85)}=4.52, p<0.05\right]$.

A post-hoc analysis across dimensions is displayed in - Figure 5. Note that the initial response profile for the consumer electronic settings-shown as the filled circles-was much lower than the other two professional settings. This finding suggests that patients who entered this setting have a moderate, predisposed perception toward the provider. For respondents with a positive outlook toward amplification, the dimensions of health promotion, patient-provider communication, and shared decision-making were found to be statistically $(p<0.05)$ lower between the pre- and postappointments. For respondents with a negative outlook toward amplification, six dimensions (of a possible ten) were statistically $(p<0.05)$ lower between the pre- and postappointment: empathy, health promotion, family/friends, provider-patient communication, respect, and shared decision-making.

\section{Discussion}

The primary interest in undertaking this study was to assess whether provider interaction influenced patient readiness toward audiological services and technology using the neobehavioral concept of need recognition in decision-making. A total of 618 respondents-all with self-perceived hearing deficits-sought out audiological care on their own from a local provider. As such, one could argue that the self-motivated patients tested in this study might have been more open to provider recommendations than patients who are forced to have their hearing assessed by a significant other or family member.

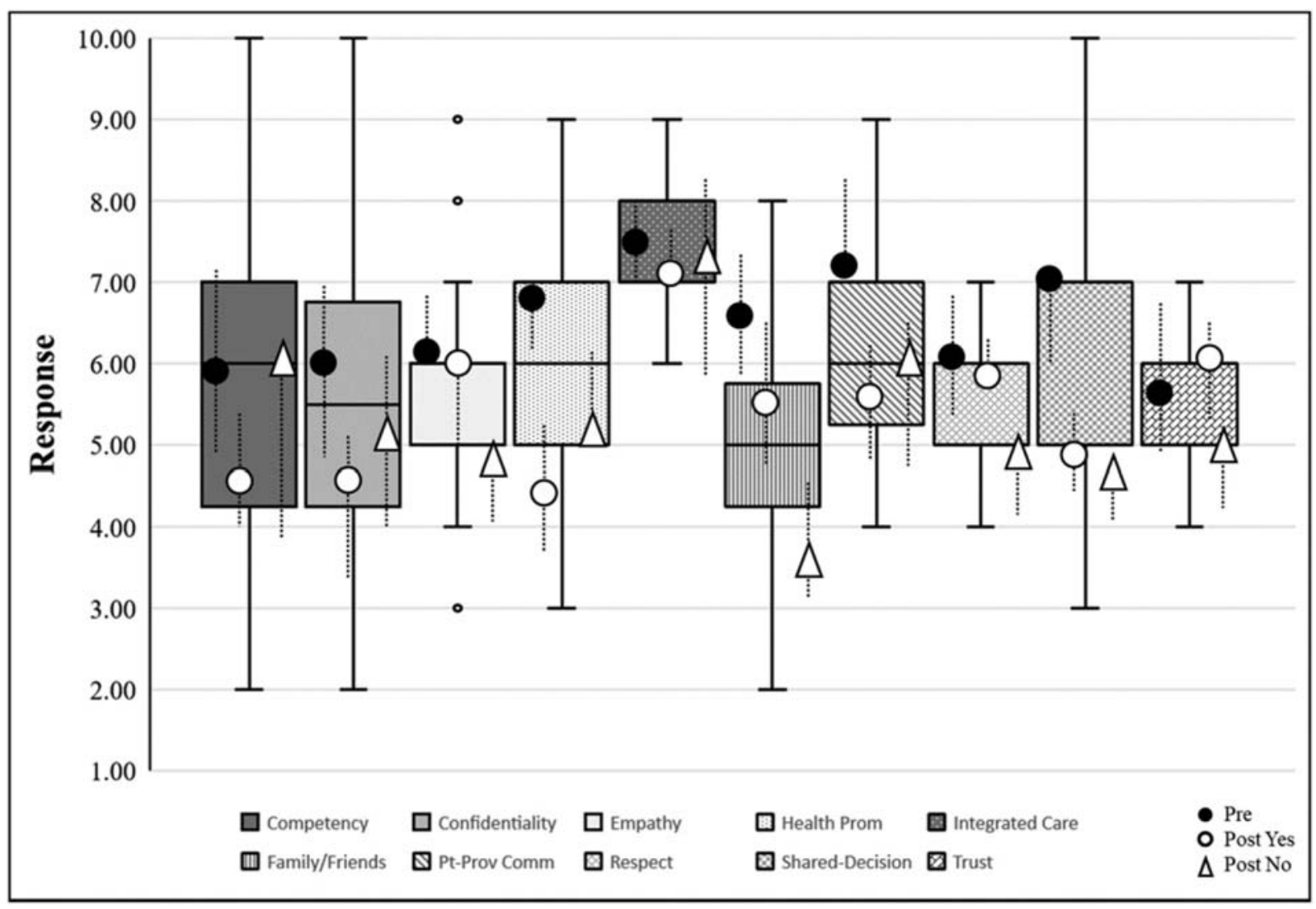

Fig. 5 Post-hoc results from the univariate ANOVA that shows quartiles (i.e., shaded rectangle) and respondents' response range (i.e., error bars) for the consumer electronic setting. The filled circles represent the preappointment mean responses among all respondents, and the open circles and open triangles, along with dashed lines representing $\mathrm{Cl} 95$, denote postappointment mean responses where respondents were positive and negative toward amplification, respectively. 
Overall, results from this study revealed that many respondents' predisposed expectations were unmet during their interaction with an audiologist. The design of the present undertaking was grounded on the principle that patients and audiologists share similar interests with respect to the treatment they receive (Laplante-Levesque, Jensen, et al). ${ }^{27}$ This study, however, revealed a disparity in ideologies between providers and patients that influence patient readiness toward adopting audiological service and technology, an outcome supported in the literature (Manchaiah et al; ${ }^{29}$ Poost-Foroosh et al.). ${ }^{36}{ }^{35}$ Poost-Foroosh et al; ${ }^{35,36}$ obtained importance ratings (i.e., $1=$ minimally important and $5=$ extremely important) from 43 adult patients and 74 providers (i.e., $\mathrm{n}=54$ audiologists and $\mathrm{n}=20$ hearing instrument specialists) on eight concepts that influence hearing aid purchase decisions. Their results revealed a disparity in mean ratings between patients and providers for the concepts of (a) understanding and meeting patient needs, (b) conveying device information by the provider, (c) shared decision-making, and (d) patient readiness.

Patient readiness was evaluated as a function of professional setting, based on the premise that professional setting provided an anchor toward respondents' predisposed perception of quality of care they expected to receive (Beattie and Nelson). ${ }^{4}$ Findings confirmed that professional setting was viewed differently by respondents seeking hearing health care. For respondents being seen by a provider in a medical setting, the outcome of - Figure 2 suggests that empathy, shared decision-making, trust, and respect were important factors for patients who are considering a trial period with amplification. For respondents considering a trial period with amplification dispensed by a provider in a rehabilitation setting (-Figure $\mathbf{2}$ ), all ten factors were considered important (i.e., \$0.40), with trust, empathy, patientprovider communication, family/friend input, and respect yielding values $\$ 0.60$. For respondents being seen by a provider in a consumer electronic setting ( - Figure 5 ), the only factor $\$ 0.40$ was family/friend input. Differences in patient expectations as a function of the care environment are also found in other health professions, such as medicine (Moore et al) $)^{33}$ and nursing (McCormack). ${ }^{31}$ The implication of this finding is that patient perception of a professional setting has the potential to either restrict or support PCC in practice, a concept that requires consideration as audiology develops its PCC framework.

The interaction between a professional setting and patient readiness toward audiological services and amplification uptake is highlighted in -Table 2. Here, results indicated that only $35 \%$ (i.e., 50 of 142 ) and $44 \%$ (i.e., 173 of 389) of respondents who entered the medical and rehabilitation settings, respectively, remained receptive toward continued audiological care offered after their appointment experience. With respect to acceptance of a recommendation with amplification, $45 \%$ (i.e., 43 of 95) and 18\% (i.e., 34 of 187 ) of respondents in the medical and rehabilitation settings, respectively, elected to pursue a trial period with amplification. Respondents in the consumer electronic setting, conversely, reported greater postappointment patient readiness toward audiological care (i.e., 88\%; 64 of 87 respondents) and uptake of amplification (i.e., 83\%; 60 of 72 respondents). For the consumer electronic group, recall that the pre- and postappointment expectations were lower than that in the medical and rehabilitation settings. These data indicate that providers who serve patients appear to be a primary barrier to patient adoption of audiological services and technology.

There are limitations to the outcomes reported in this study, mostly with respect to external validity. First, we lack information on the characteristics that prompted patients to schedule an appointment with the provider they chose. Second, we have no knowledge of what transpired during the appointment session. We hope to examine the dynamics between providers and patients in a future study. Last, the outcomes from this study do not provide sufficient evidence of the short- and long-term perceptions of patients toward providers, and the manner in which these perceptions lend to impaired listeners either not treating or delaying treatment to overcome their communication difficulties. We do know that once attitude is predisposed, changing that predisposition is difficult (Wilson et al). ${ }^{51}$

Finally, we quantified the influence of provider interaction on patient readiness using the principle of need recognition ( - Figure 1) described in consumer decisionmaking to overcome the sensitivity limitations of health-behavior models in quantifying changes in a person's attitudes, beliefs, and motivation. The findings from this study support the informationprocessing perspective (i.e., need recognition) as a sensitive tool and, perhaps, a decision aid (According to Cox (2014), "a decision aid is a visual tool that helps organize and sys- temize a set of options. Audiologists can use it to facilitate a conversation with the patient to help him decide on a treatment plan.") for the provider in quantifying changes in patient perception of impaired listeners toward the health-care services they receive. Such a tool or aid could also be used by providers as a self-evaluation tool of their management skills in the treatment of patients with impaired hearing.

\section{Abbreviations}

ANOVA analysis of variance

$\mathrm{Cl}_{95} \quad$ 95-percent confidence interval

PCC patient-centered care

SD standard deviation

Conflict of Interest

None declared.

Acknowledgments

The author expresses his thanks to the anonymous reviewers for their comments and suggestions.

\section{References}

1 Amlani AM. Application of the Consumer Decision-Making Model to hearing aid adoption in first-time users. Sem Hear 2016;37 (02):103-119 
2 Amlani AM, Taylor B, Weinberg T. Increasing hearing aid adoption rates through value-based advertising and price unbundling. Hear Rev 2011;18:10-17

3 Barry MJ, Edgman-Levitan S. Shared decision-making - the pinnacle of patient-centered care. New Engl J Med 2012; 366:780-781

4 Beattie PF, Nelson RM. Preserving the quality of the patienttherapist relationship: an important consideration for valuecentered physical therapy care. J Orthop Sport Phys Ther 2008; 38(02):34-35

5 Blackwell RD, Miniard PW, Engel JF. Consumer Behavior. Fort Worth, TX: Harcourt Brace College; 2001

6 Boisvert I, Clemesha J, Lundmark E, Crome E, Barr C, McMahon $\mathrm{CM}$. Decision-making in audiology: balancing evidence-based practice and patient-centered care. Trend Hear 2017;21:1-14

7 Childers TL, Rao AR. The influence of familial and peerbased reference groups on consumer decisions. J Consum Res 1992;19 (02):198-211

8 Coulson NS, Ferguson MA, Henshaw H, Heffernan E. Applying theories of health behavior and change to hearing health research: time for a new approach. Int J Audiol 2016;55(03):S99-S104

9 Cox R. 20Q: hearing aid provision and the challenge of change. Audiol Online, Article 12596. 2014https://www.audiologyonline. com. Accessed October 7, 2019

10 Ekberg K, Barr C, Hickson L. Difficult conversations: talking about cost in audiology consultations with older adults. Int J Audiol 2017;56(11):854-861

11 Ekberg K, Grenness C, Hickson L. Addressing patients' psychosocial concerns regarding hearing aids within audiology appointment for older adults. Am J Audiol 2014;23(03):337-350

12 Ekberg K, Grenness C, Hickson L. Application of the transtheoretical model of behaviour change for identifying older clients' readiness for hearing rehabilitation during history taking in audiology appointments. Int J Audiol 2016;55(03):S42-S51

13 Ekberg K, Meyer C, Scarinci N, Grenness C, Hickson L. Family member involvement in audiology appointments with older people with hearing impairment. Int J Audiol 2015;54(02): 70-76

14 Fishbein M, Ajzen I. Belief, Attitude, Intention, and Behavior: An Introduction to Theory and Research. Reading, MA: AddisonWesley; 1975

15 Frederick AA, Prins N. Psychophysics: A Practical Introduction. San Diego, CA: Academic Press; 2016

16 Gilligan J, Weinstein BE. Health literacy and patientcentered care in audiology-implications for adult aural rehabilitation. J Comm Dis Deaf Stud Hear Aids 2014;2:110

17 Gröne O, Garcia-Barbero M. Integrated care. Int J Integr Care 2001; 1(02):e21

18 Grenness C, Hickson L, Laplante-Léevesque A, Davidson B. Patientcentered care: a review of rehabilitative audiologists. Int J Audiol 2014a53(01):S60-S67

19 Grenness C, Hickson L, Laplante-Lévesque A, Davidson B. Patientcentered audiological rehabilitation: perspectives of older adults who own hearing aids. Int J Audiol 2014b53(01):S68-S75

20 Grenness C, Hickson L, Laplante-Lévesque A, Meyer C, Davidson B. The nature of communication throughout diagnosis and management planning in initial audiologic rehabilitation consultations. J Am Acad Audiol 2015;26(01):36-50

21 Hibbard JH. Patient activation and the use of information to support informed health decisions. Patient Educ Couns 2016; 100(01):5-7

22 Institute of Medicine (US) Committee on Quality of Health Care in America. Crossing the Quality Chasm: A New Health System for the 21st Century. Washington, DC: National Academy Press; 2001

23 Kirande K, Merchant A, Sivakumar K. Relationship among time orientation, consumer innovativeness, and innovative behavior: the moderating role of product characteristics. Acad Market Sci 2011;1:99-116

24 Koutsimanis G, Getter K, Behe B, Harte J, Almenar E. Influences of packing attributes on consumer purchase decisions for fresh produce. Appetite 2012;59:270-280

25 Laplante-Léevesque A, Hickson L, Worrall L. What makes adults with hearing impairment take up hearing aids or communication programs and achieve successful outcomes? Ear Hear 2012;33 (01):83-92

26 Laplante-Lévesque A, Hickson L, Worrall L. Stages of change in adults with acquired hearing impairment seeking help for the first time: application of the transtheoretical model in audiologic rehabilitation. Ear Hear 2013;34(04): 447-457

27 Laplante-Lévesque A, Jensen LD, Dawes P, Nielsen P. Optimal hearing aid use: focus groups with hearing aid clients and audiologists. Ear Hear 2013;34(02):193-202

28 Lutfey KE, Gerstenberger E, McKinlay JB. Physician styles of patient management as a potential source of disparities: cluster analysis from a factorial experiment. Health Serv Res 2013;48 (03):1116-1134

29 Manchaiah VKC, Stephens D, Meredith R. The patient journey of adults with hearing impairment: the patient's views. Clin Otolaryngol 2011;36(03):227-234

30 Martćc-Kehl MI, Wernery J, Folkers G, Schubiger PA. Quality of animal experiments in anti-angiogenic cancer drug development-a systematic review. PLoS One 2015;10(09):e0137235

31 McCormack B. Person-centredness in gerontological nursing: an overview of the literature. J Clin Nurs 2004;13:31-38

32 McCormack B, McCance TV. Development of a framework for person-centered nursing. J Adv Nurs 2006;56(05):472-479

33 Moore L, Britten N, Lydahl D, Naldemirci Ö, Elam M, Wolf A. Barriers and facilitators to the implementation of personcentered care in different healthcare contexts. Scand J Caring Sci 2017; 31:662-673

34 Østergaard O, Jantzen C. Shifting perceptive in consumer research: from buyer behavior to consumption studies. In: Beckman SC, Elliott RH, eds. Interpretive Consumer ResearchParadigms, Methodologies, and Applications. Copenhagen: Handelshøjskolens Forlag; 2000:9-23

35 Poost-Foroosh L, Jennings MB, Cheesman MF. Comparison of client and clinician views of the importance factors in clientclinician interaction in hearing aid purchase decisions. J Am Acad Audiol 2015;26(03):247-259

36 Poost-Foroosh L, Jennings MB, Shaw L, Meston CN, Cheesman MF. Factors in client-clinician interaction that influence hearing aid adoption. Trends Amp 2011;15(03):127-139

37 Preminger JE, Oxenbøll M, Barnett MB, Jensen LD, LaplanteLevesque A. Perceptions of adults with hearing impairment regarding the promotion of trust in hearing healthcare service delivery. Int J Audiol 2015;54:20-28

38 Prochaska JO, DiClemente CC. The transtheoretical approach. In: Norcross JC, Goldfried MR, eds. Handbook of Psychotherapy Integration: Oxford Series in Clinical Psychology. 2nd ed. Oxford: Oxford University Press; 2005:147-171

39 Qamar N, Pappalarado AA, Arora VM, Press VG. Patientcentered care and its effect on outcomes in the treatment of asthma. Patient Relat Outcome Meas 2011;2:81-109

40 Rogers CR. Client-Centered Therapy: It's Current Practice, Implications and Theory. Boston, MA: Houghton Mifflin; 1951

41 Rosenstock IM. Why people use health services. Milbank Q 1966; 44(03):94-127

42 Saha S, Beach MC, Cooper LA. Patient centeredness, cultural competence, and healthcare quality. J Natl Med Assoc 2008;100 (11):1275-1285

43 Salovey P, Rothman AJ, Rodin J. Health Behavior. New York, NY: McGraw-Hill; 1998 
44 Santana MJ, Manalili K, Jolley RJ, Zelinsky S, Quan H, Lu M. How to practice person-centered care: a conceptual framework. Health Expect 2018;21(02):429-440

45 Saunders GH, Frederick MT, Silverman S, Papesh M. Application of the health belief model: development of the Hearing Beliefs Questionnaire (HBQ) and its associations with hearing health behaviors. Int J Audiol 2013;52(08):558-567

46 Schiffman LG, Wisenblit JL. Consumer Behavior. 11th ed. Boston, MA: Pearson; 2013

47 Stepien K, Baernstein A. Educating for empathy. J Gen Intern Med 2006;21(05):524-530
48 Storbeck J, Clore GL. On the interdependence of cognition and emotion. Cogn Emot 2007;21(06):1212-1237

49 Thom DH, Campbell B. Patient-physician trust: an exploratory study. J Fam Pract 1997;44:169-176

50 Thom DH, Hall MA, Pawlson LG. Measuring patients' trust in physicians when assessing quality of care. Health Aff (Millwood) 2004;23:124-132

51 Wilson TD, Lindsey S, Schooler TY. A model of dual attitudes. Psychol Rev 2000;107(01):101-126 